\title{
Periventricular Heterotopia in Common Microdeletion Syndromes
}

\author{
$\begin{array}{llll}\text { M. van Kogelenberg } & \text { a S. Ghediab } & \text { G. McGillivrayc } & \text { D. Bruno } \\ & \text { d R. Leventer } & \end{array}$ \\ K. MacDermot ${ }^{f} \quad$ J. Nelson ${ }^{g} \quad$ L. Nagarajan ${ }^{\text {h }} \quad$ J.A. Veltman ${ }^{i} \quad$ A.P. de Brouwer ${ }^{i}$ \\ R.J. McKinlay Gardner ${ }^{\mathrm{a}}$ H. van Bokhoven ${ }^{i}$ E.P. Kirk ${ }^{\mathrm{b}}$ S.P. Robertson ${ }^{\mathrm{a}}$ \\ ${ }^{a}$ Department of Paediatrics and Child Health, Dunedin School of Medicine, Otago University, Dunedin, \\ New Zealand; 'b Department of Medical Genetics, Sydney Children's Hospital, Sydney, N.S.W., \\ 'Genetic Health Services Victoria, ${ }^{\mathrm{d} C y t o g e n e t i c s ~ D e p a r t m e n t, ~ a n d ~}{ }^{\mathrm{e} C h i l d r e n ' s ~ N e u r o s c i e n c e ~ C e n t r e ~ a n d ~}$ \\ Murdoch Children's Research Institute, Royal Children's Hospital, Melbourne, Vic., Australia; \\ ${ }^{f}$ North West Thames Regional Genetics Service, Harrow, UK; ${ }^{9}$ Genetic Service of Western Australia, \\ King Edward Memorial Hospital for Women, and hepartment of Neurology, Princess Margaret Hospital \\ for Children, Perth, W.A., Australia; 'Department of Human Genetics, Radboud University Nijmegen \\ Medical Centre, Nijmegen, The Netherlands
}

\section{Key Words}

Periventricular heterotopia • Microdeletion syndrome •

Neuronal migration

\begin{abstract}
Periventricular heterotopia $(\mathrm{PH})$ is a brain malformation characterised by heterotopic nodules of neurons lining the walls of the cerebral ventricles. Mutations in FLNA account for $20-24 \%$ of instances but a majority have no identifiable genetic aetiology. Often the co-occurrence of $\mathrm{PH}$ with a chromosomal anomaly is used to infer a new locus for a Mendelian form of $\mathrm{PH}$. This study reports four $\mathrm{PH}$ patients with three different microdeletion syndromes, each characterised by high-resolution genomic microarray. In three patients the deletions at 1 p36 and 22q11 are conventional in size, whilst a fourth child had a deletion at 7q11.23 that was larger in extent than is typically seen in Williams syndrome. Although some instances of $\mathrm{PH}$ associated with chromosomal deletions could be attributed to the unmasking of a reces-
\end{abstract}

sive allele or be indicative of more prevalent subclinical migrational anomalies, the rarity of $\mathrm{PH}$ in these three microdeletion syndromes and the description of other non-recurrent chromosomal defects do suggest that $\mathrm{PH}$ may be a manifestation of multiple different forms of chromosomal imbalance. In many, but possibly not all, instances the co-occurrence of $\mathrm{PH}$ with a chromosomal deletion is not necessarily indicative of uncharacterised underlying monogenic loci for this particular neuronal migrational anomaly.

Copyright ๑ 2010 S. Karger AG, Basel

Periventricular heterotopia $(\mathrm{PH})$ is a genetically heterogeneous neuronal migration disorder characterised by the presence of subependymal heterotopic nodules. These nodules are composed of postmitotic neurons that have failed to initiate migration from the sub-ventricular zone to their proper destination within the cerebral cortex during embryonic and fetal development [Fox et al., 1998]. The clinical presentation of isolated $\mathrm{PH}$ includes

\section{KARGER \\ Fax +4161306 1234 \\ E-Mail karger@karger.ch}

www.karger.com
(C) 2010 S. Karger AG, Basel

$1661-8769 / 10 / 0011-0035 \$ 26.00 / 0$

Accessible online at:

www.karger.com/msy 
Table 1. Cases of chromosomal imbalances in which $\mathrm{PH}$ have been described

\begin{tabular}{|c|c|c|c|c|c|}
\hline Segment & Syndromic diagnosis & Balanced, del or dup & $\mathrm{n}$ & PH distribution & Reference \\
\hline $\mathrm{t}(1 ; 6)(\mathrm{p} 12 ; \mathrm{p} 12.2)$ & - & apparently balanced & 1 & Bilateral & Leeflang et al., 2003 \\
\hline $1 \mathrm{p} 36$ & 1p36 del syndrome & del & 1 & Bilateral & Neal et al., 2006 \\
\hline $1 \mathrm{p} 36$ & 1p36 del syndrome & del & 1 & Unilateral & Saito et al., $2008^{a}$ \\
\hline $1 \mathrm{p} 36$ & 1p36 del syndrome & del & 1 & Unilateral & Present case 1 \\
\hline $4 \mathrm{p} 14-\mathrm{p} 15.32^{\mathrm{d}}$ & Proximal 4p del syndrome & del & 1 & Unilateral & Gawlik-Kuklinska et al., 2008 \\
\hline $5 \mathrm{p} 15$ & - & dup & 2 & Bilateral & Sheen et al., 2003 \\
\hline $\operatorname{mos} 46, \mathrm{XX}, \operatorname{der}(5)^{\mathrm{e}}$ & Cri du chat & del & 1 & Unilateral & Tsao et al., 2005 \\
\hline $5 q 14.3-q 15$ & - & del & 3 & Bilateral & Cardoso et al., 2009 \\
\hline $7 q 11$ & Williams syndrome & del & 1 & Bilateral & Ferland et al., $2006^{\mathrm{a}}$ \\
\hline $7 q 11$ & Williams syndrome & del & 1 & Bilateral & Present case $4^{\mathrm{a}}$ \\
\hline $12 \mathrm{q} 24.3$-qter & - & dup & 1 & Bilateral & Grosso et al., 2008 ${ }^{\mathrm{b}}$ \\
\hline 17 p13.3-pter & - & del & 1 & & Grosso et al., $2008^{\mathrm{b}}$ \\
\hline $\operatorname{der}(19) t(X ; 19)(q 11.12 ; p 13.3) c$ & - & & 1 & Bilateral & Balci et al., 2007 \\
\hline $22 \mathrm{q} 11$ & 22q11del syndrome & del & 1 & Bilateral & Kiehl et al., 2008 \\
\hline $22 \mathrm{q} 11$ & 22q11del syndrome & del & 1 & Bilateral & Present case 2 \\
\hline $22 \mathrm{q} 11$ & 22q11del syndrome & del & 1 & Bilateral & Present case 3 \\
\hline $\mathrm{Xp} 22.3$ & Steroid sulphatase deficiency & del & 1 & Bilateral & Ozawa et al., 2006 \\
\hline $\mathrm{Xq} 28$ & BPNH-syndactyly & dup & 1 & Bilateral & Fink et al., 1997 \\
\hline
\end{tabular}

epileptic seizures and often cognitive disability that can range from dyslexia [Chang et al., 2005] to severe mental retardation [Parrini et al., 2006]. Additional extracerebral anomalies include cardiovascular malformations, haematological manifestations, and connective tissue defects [Fox et al., 1998; Sheen et al., 2001, 2005; Parrini et al., 2006]. Although most individuals with $\mathrm{PH}$ do not have an assigned aetiology [Parrini et al., 2006], two loci have so far been identified. X-linked PH is due to mutations in the gene encoding filamin A (FLNA) [Fox et al., 1998], whereas mutations in ARFGEF2, encoding ADPribosylation factor guanine nucleotide exchange factor 2 , cause a rare autosomal recessive disorder of $\mathrm{PH}$ with microcephaly [Sheen et al., 2004]. The majority of familial cases of $\mathrm{PH}$ are due to an alteration in FLNA, in contrast to sporadic PH cases where only $20-24 \%$ have been identified with a mutation in this gene [Sheen et al., 2001; Parrini et al., 2006].

$\mathrm{PH}$ is also occasionally observed as a concomitant feature in a small number of syndromes [Sheen et al., 2005; Banerjee et al., 2006; Moro et al., 2006; Ruggieri et al., 2007; Spinosa et al., 2007] and chromosome disorders [Leeflang et al., 2003; Sheen et al., 2003; Ferland et al., 2006; Neal et al., 2006; Balci et al., 2007; Gawlik-Kuklins- ka et al., 2008; Grosso et al., 2008; Cardoso et al., 2009] including well-delineated conditions such as cri-du-chat syndrome and the 22q11 deletion syndrome [Tsao et al., 2005; Kiehl et al., 2008]. Several of these descriptions have prompted speculation that novel $\mathrm{PH}$ loci might lie within these deleted regions, invoking haploinsufficiency for a critical gene as the proposed mechanism [Sheen et al., 2003; Ferland et al., 2006; Neal et al., 2006; GawlikKuklinska et al., 2008], a contention strengthened by the characterisation of deletions that are larger than commonly seen in the 1 p36 deletion syndrome and in Williams syndromes [Ferland et al., 2006; Neal et al., 2006; Saito et al., 2008]. With the notable exceptions of anomalies noted on 5p15 [Sheen et al., 2003] and 5q11 [Cardoso et al., 2009], very few of these described chromosomal anomalies have been recurrently and consistently observed in association with $\mathrm{PH}$ (table 1).

Extending this experience, this study describes four patients with three commonly encountered microdeletion syndromes. In three cases, one instance of $1 \mathrm{p} 36 \mathrm{de}-$ letion and 2 cases with 22q11 deletion syndrome, the deletion size is similar to those commonly reported in these conditions. A fourth individual has a deletion at $7 \mathrm{q} 11.23$ that extends beyond the size usually observed in 
association with Williams syndrome. Since the size of the $1 \mathrm{p} 36$ and $22 \mathrm{q} 11$ deletions was typical for these recurrently occurring deletions, we consider the possibility that $\mathrm{PH}$ loci may exist nearby (but outside the classic deletion regions) to be unlikely. Rather, and taking note that $\mathrm{PH}$ has been reported predominantly in association with a host of non-recurrent chromosomal abnormalities, we propose that $\mathrm{PH}$ may be a lowly penetrant and non-specific manifestation of many forms of chromosomal imbalance.

\section{Methods}

Ethical Review, Consent and Patient Ascertainment

All subjects were ascertained by physician-initiated referral and consented to participate under an approved institutional protocol. All individuals had a normal G-banded karyotype.

\section{Genomic Copy Number Variation Assay}

Copy number variation mapping was performed using Affymetrix $250 \mathrm{k} N s p$ I array, according to the manufacturer's protocol (Affymetrix; Santa Clara, Calif., USA). Copy number estimates were determined automatically in the CNAG 2.0 software package by a hidden Markov model [Nannya et al., 2005].

\section{Quantitative PCR (qPCR)}

qPCR was performed on genomic DNA with an ABI 7300 realtime PCR machine (Applied Biosystems, Carlsbad, Calif., USA) using SYBR green for detection. The reaction mix contained $8 \mu \mathrm{M}$ of each primer and $12 \mu \mathrm{l}$ iQ SYBR Green Supermix (BioRad, Hercules, Calif., USA). Patient DNA was added to a final concentration of $0.25 \mathrm{ng} / \mu \mathrm{l}$, in a total reaction volume of $25 \mu \mathrm{l}$. Each assay included a no-template control and male or female control DNA. All reactions were performed in duplicate. Results were normalised with two autosomal loci (CFTR and TRAF2) and SLC16A2 on the X chromosome. $2^{\Delta \Delta C T}$ was calculated as previously described [Livak and Schmittgen, 2001]. Cycling protocols and primer sequences are available on request.

\section{FISH}

FISH was performed using RP11-54O7 and p58 BAC clones as probes at $1 \mathrm{p} 36$ and the Tuple1 probe at $22 \mathrm{q} 11$ to confirm deletions at these sites.

\section{Clinical Reports}

All patients presented with an apparently normal karyotype, and screening FLNA for point mutations was negative.

\section{Patient 1}

The patient (fig. 1a, e) is the second child of unrelated healthy parents. He was born at 37 weeks gestation by Caesarean section as a result of fetal distress. Family history was non-contributory. He presented with intractable epileptic seizures from 10 weeks of age. He had severe global developmental delay. Brain MRI at age
11 identified unilateral periventricular nodular heterotopia and bilateral white matter gliosis with under-myelination in the deep white matter of both parietal lobes and a cavum septum pellu-

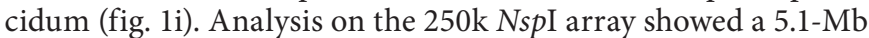
telomeric deletion at $1 \mathrm{p} 36$ extending from rs2980300 to rs 4076635 (fig. 2a, b). FISH and qPCR confirmed the deletion, and examination of parental samples indicated it had occurred as a de novo event.

\section{Patient 2}

The patient (fig. $1 \mathrm{~b}, \mathrm{f}$ ) is the second child of healthy unrelated parents. There was no notable family disease history. During pregnancy a mega cisterna magna was identified, leading to an MRI scan after birth. The scan revealed symmetrical bilateral PH lining the lateral ventricles, especially the ventricular bodies, with limited extension into the frontal horns (fig. 1j). Epileptic seizures have not been observed. She has mild global developmental delay and joint hypermobility. At 5 months of age she developed febrile neutropenia and pancytopenia; however, bone marrow examination demonstrated normal morphology and haematological indices subsequently returned to normal. Array analysis showed a $\sim 3-\mathrm{Mb}$ deletion at 22q11 extending from rs418623 to rs140390. The qPCR analysis confirmed the extent of the deletion and indicated that it had occurred as a de novo event.

\section{Patient 3}

The patient (fig. 1c, g) is the second child born to healthy unrelated parents. The pregnancy was complicated by polyhydramnios, prompting induction of labour at 38 weeks. He initially presented with febrile convulsions, which evolved into non-febrile seizures from 8 months of age. Subsequently, global developmental delay has become evident. Clinical features suggestive of 22q11 deletion syndrome were noted: relative short stature, cupped ears, submucosal cleft palate, long, tapered fingers and generalised joint hypermobility (fig. 1c, g). There was no congenital heart defect present. Brain MRI at age 8 years revealed multiple nodules of heterotopic grey matter lining the bodies of the lateral ventricles and the temporal horns (fig. 1k). FISH analysis showed a deletion at 22q11 which was confirmed to be $\sim 3 \mathrm{Mb}$ in extent by qPCR. Analysis of parental samples using FISH indicated that it had occurred as a de novo event.

\section{Patient 4}

The patient (fig. 1d, h) was the child of healthy non-related parents born after an unremarkable pregnancy. There were concerns regarding delayed development from 4 months of age and he developed infrequent generalised seizures from age two years onwards. He had short stature (3rd centile), a wide-based gait, and an intention tremor. Additional dysmorphic features were noted: prominent upper lip with wide-spaced upper incisors and overbite, flexion contractures of elbows, knees, and fingers, thoracic kyphosis, and marked lumbar gibbus; radiology demonstrated lumbar vertebral anomalies. The cardiac examination was normal, and renal function was intact. Brain MRI identified bilateral heterotopic grey matter predominantly located in the frontal horns, mild hypoplasia of the cerebellum, and an enlarged retrocerebellar space (fig. 11). Array analysis showed a $3.5-\mathrm{Mb}$ de novo deletion at 7q11.23 from rs12539763 to rs1019096 confirmed by qPCR analysis (fig. 2c, d). 

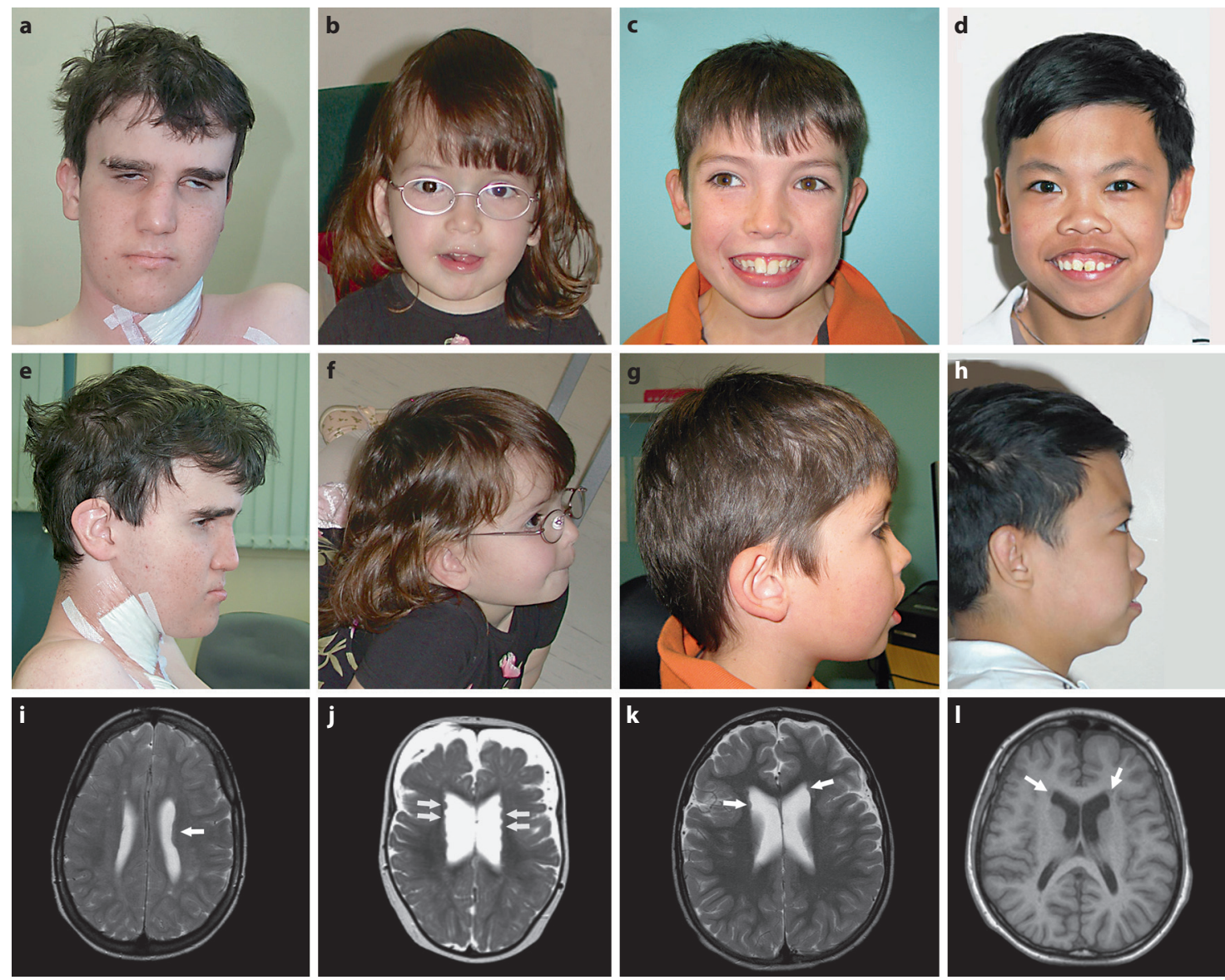

Fig. 1. Clinical presentation of patient $1(\mathbf{a}, \mathbf{e}, \mathbf{i})$ with $1 \mathrm{p} 36$ deletion syndrome, patient $2(\mathbf{b}, \mathbf{f}, \mathbf{j})$ with $22 \mathrm{q} 11$ deletion syndrome, patient $3(\mathbf{c}, \mathbf{g}, \mathbf{k})$ with $22 \mathrm{q} 11$ deletion syndrome, and patient 4 (d, h, I) with Williams syndrome. Brain imaging demonstrated nodular heterotopia that was unilateral in patient $1(\mathbf{i})$, bilateral and symmetrical in patient $2(\mathbf{j})$, lined the bodies of the lateral ventricles in patient $3(\mathbf{k})$, and was present in the frontal horns in patient $4(\mathbf{I})$.

\section{Discussion}

Previous reports have interpreted the association of $\mathrm{PH}$ with a chromosomal anomaly as likely reflecting a causal relationship attributable to disruption of function of a single gene within the deleted interval [Leeflang et al., 2003; Sheen et al., 2003; Neal et al., 2006; Grosso et al., 2008; Cardoso et al., 2009]. However, the description of the association of $\mathrm{PH}$ with four well-studied microdeletion syndromes, and with a number of other single instances of rare or unique chromosomal imbalances (table 1), suggests that many chromosomal anomalies have the potential to disrupt neuronal migration and lead to $\mathrm{PH}$, usually with low penetrance. Rather than implicating specific loci that might have a direct effect, these data suggest that $\mathrm{PH}$ may be the downstream effect of many different types of chromosomal imbalance and as such be a final common manifestation of multiple genetic lesions that impair neuronal development. Other manifestations of abnormal neuronal migration such as polymicrogyria, and agenesis of the corpus callosum in 1p36 [Gajecka et al., 2007; Battaglia et al., 2008], 22q11 [Kraynack et al., 1999; Robin et al., 2006], and grey matter anomalies in Williams syndrome [Jernigan and Bellugi, 1990; Mercuri et al., 1997; Boddaert et al., 2006; Chiang et al., 2007] underscore this point.

The rare observation of $\mathrm{PH}$ with microdeletions in the patients described in this report, and more broadly in other chromosomal anomalies, may therefore reflect that this sign is a relatively non-specific end result of multiple pathways that impair neuronal migration, rather than the more specific and penetrant effect of an underlying mutated 


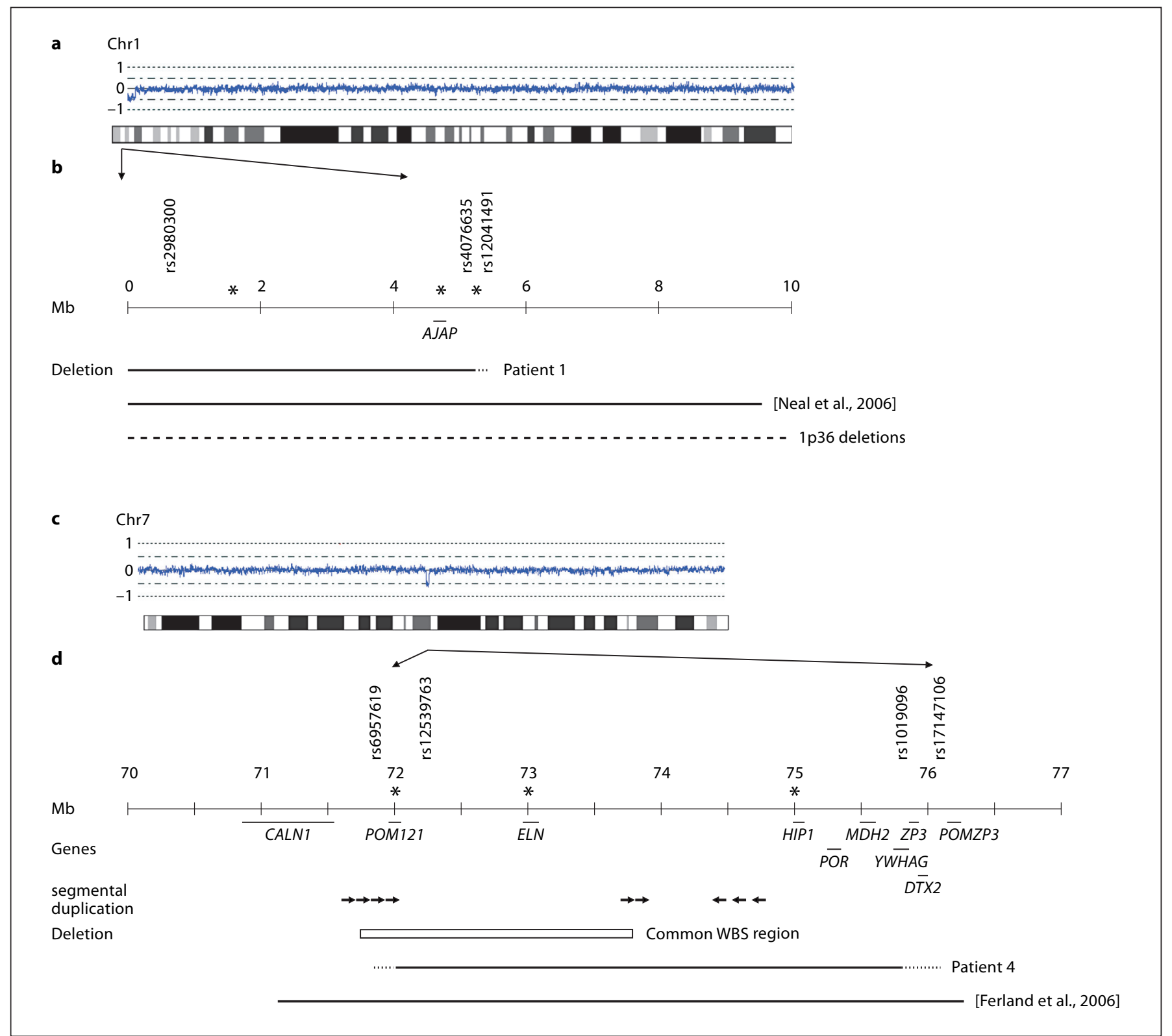

Fig. 2. Graphic overview of deletions identified in patient 1 and 4 . a Normalised CNAG data trace from the 250k SNP array with a deletion at 1p36. b Diagram of the deleted region in patient 1 , the deletion previously reported in association with $\mathrm{PH}$ [Neal et al., 2006] and the range of deletion sizes identified in the 1 p36 deletion syndrome. c Normalised CNAG data trace from the $250 \mathrm{k}$ SNP array with a deletion at 7q11. $\mathbf{d}$ Diagram of the deleted region

gene such as FLNA or ARFGEF2. In an analogous fashion several chromosomal loci have been proposed to underlie polymicrogyria [Dobyns et al., 2008] but here, in contrast to the situation with $\mathrm{PH}$, the chromosomal associations have been recurrent and consistent, a finding more in

Periventricular Nodular Heterotopia and Microdeletions in patient 4 , a deletion previously described in a patient with $\mathrm{PH}$ and Williams syndrome [Ferland et al., 2006], and the region typically deleted in Williams syndrome. The solid black line indicates the extent of the deleted region; the hatched line denotes potentially deleted sequences. * signifies loci for confirmatory FISH and qPCR.

keeping with a susceptibility conferred by hapolinsufficiency for one or a number of underlying genes in those regions. Of the described loci so far associated with $\mathrm{PH}$, only duplications in 5p15 [Sheen et al., 2003] and deletions in 5q11 [Cardoso et al., 2009] may fulfill these criteria. 
It was reasonable for Neal et al. [2006] and Saito et al. [2008] to suggest the existence of a PH gene at 1 p36 on the grounds that the deletions they described extended further towards the centromere than deletions typically observed in $1 \mathrm{p} 36$ deletion syndrome. Now that a patient with $\mathrm{PH}$ has been described with a 5-Mb telomeric $1 \mathrm{p} 36$ deletion, this proposition is weakened although a lowly penetrant position effect remains a formal possibility and molecular and imaging studies of further individuals with a 1p36 deletion will help clarify this issue.

In contrast to the rare occurrence of $\mathrm{PH}$ with deletion sizes commonly encountered at $1 \mathrm{p} 36$ and 22q11, the observation of two overlapping atypical deletions leading to $\mathrm{PH}$ and Williams syndrome may be indicative of a defined susceptibility locus on 7q11 that predisposes to neuronal migration abnormalities. Williams syndrome is caused by deletions at 7q11.23, typically $\sim 1.55 \mathrm{Mb}$ long and affecting $\sim 28$ genes. A small proportion of patients have larger deletions [Stock et al., 2003; Ferland et al., 2006; Marshall et al., 2008]. PH has been previously described in association with Williams syndrome in one patient [Ferland et al., 2006]. A deletion extending 1.5 Mb beyond the telomeric region of the common Williams syndrome deletion interval was defined and affected an additional 16 genes, one or some of which were proposed to be susceptibility genes leading to $\mathrm{PH}$ [Ferland et al., 2006]. The atypical 3.6-Mb deletion described here extends telomeric to the common Williams syndrome region, overlapping the $1.5-\mathrm{Mb}$ region described by Ferland et al. [2006], supporting this possibility. Previously described patients with similar or overlapping deletions in the Williams syndrome region [Stock et al., 2003; Marof these individuals would be useful to determine the frequency of $\mathrm{PH}$ and its relationship to these mapped haploinsufficient regions. ber of cases of these classical deletion syndromes - 1p36, $5 \mathrm{p}, 7 \mathrm{q} 11$, and 22q11 - in which $\mathrm{PH}$ have been detected is small. However, the true prevalence might well be underof these (or of numerous other) chromosome deletion syndromes. Equally, a child manifesting severe seizures (as in case 1), ahead of the chromosome diagnosis, would be more likely to have cerebral imaging, thus leading to a bias in favour of PH detection. Less likely explanations include the potential for a de novo deletion to unmask the presence of a recessive allele in trans or that the phenotype is

The foregoing observations identified by genomewide high-resolution copy number variation analysis suggest that some instances of $\mathrm{PH}$ may not necessarily have a primarily monogenic aetiology, and that associations with chromosomal anomalies [Leeflang et al., 2003; Sheen et al., 2003; Ferland et al., 2006; Neal et al., 2006; Balci et al., 2007; Gawlik-Kuklinska et al., 2008; Grosso et al., 2008] are not necessarily indicative of underlying uncharacterised loci. These observations of $\mathrm{PH}$ in association with multiple different chromosomal rearrangements confirm the aetiologically heterogeneous nature of $\mathrm{PH}$. Although the occurrence of de novo deletions, in association with sporadically arising phenotypic traits, remains a powerful method of identifying highly penetrant disease-causing genes [Vissers et al., 2005], this study suggests that such an inference may be less secure in cases where $\mathrm{PH}$ is the phenotypic feature of interest. We suggest that, in selected cases, MRI brain scanning in these and other chromosomal deletion/duplication syndromes may be warranted, in order to cast further light upon this question.

\section{Acknowledgements}

We are grateful to the families who participated in this study. This study was supported by the Child Health Research Foundation of New Zealand. shall et al., 2008] have been reported and neuroimaging

Our hypothesis carries a number of caveats. The numestimated, given that MRI brain scanning is not routinely performed in children with established diagnoses of one entirely unrelated to these described microdeletions.

\section{References}

40

Mol Syndromol 2010;1:35-41
- Balci S, Unal A, Engiz O, Aktas D, Liehr T, et al: Bilateral periventricular nodular heterotopia, severe learning disability, and epilepsy in a male patient with $46, \mathrm{XY}, \operatorname{der}(19) \mathrm{t}(\mathrm{X} ; 19)$ (q11.1-11.2;p13.3). Dev Med Child Neurol 49:219-224 (2007).

-Banerjee TK, Chattopadhyay A, Manglik AK, Ghosh B: Aicardi syndrome: a report of five Indian cases. Neurol India 54:91-93 (2006).

- Battaglia A, Hoyme HE, Dallapiccola B, Zackai E, Hudgins L, et al: Further delineation of deletion $1 \mathrm{p} 36$ syndrome in 60 patients: a recognizable phenotype and common cause of developmental delay and mental retardation. Pediatrics 121:404-410 (2008).

- Boddaert N, Mochel F, Meresse I, Seidenwurm D, Cachia A, et al: Parieto-occipital grey matter abnormalities in children with Williams syndrome. Neuroimage 30:721-725 (2006).

Cardoso C, Boys A, Parrini E, Mignon-Ravix C, McMahon JM, et al: Periventricular heterotopia, mental retardation, and epilepsy associated with 5q14.3-q15 deletion. Neurology 72:784-792 (2009). 
-Chang BS, Ly J, Appignani B, Bodell A, Apse KA, et al: Reading impairment in the neuronal migration disorder of periventricular nodular heterotopia. Neurology 64:799-803 (2005).

Chiang MC, Reiss AL, Lee AD, Bellugi U, Galaburda AM, et al: 3D pattern of brain abnormalities in Williams syndrome visualized using tensor-based morphometry. Neuroimage 36:1096-1109 (2007).

Dobyns WB, Mirzaa G, Christian SL, Petras K, Roseberry J, et al: Consistent chromosome abnormalities identify novel polymicrogyria loci in 1p36.3, 2p16.1-p23.1, 4q21.21-q22.1, 6q26-q27, and 21q2. Am J Med Genet A 146A:1637-1654 (2008).

-Ferland RJ, Gaitanis JN, Apse K, Tantravahi U, Walsh CA, Sheen VL: Periventricular nodular heterotopia and Williams syndrome. Am J Med Genet A 140:1305-1311 (2006).

- Fink JM, Dobyns WB, Guerrini R, Hirsch BA: Identification of a duplication of Xq28 associated with bilateral periventricular nodular heterotopia. Am J Hum Genet 61:379-387 (1997).

-Fox JW, Lamperti ED, Ekşioğlu YZ, Hong SE, Feng Y, et al: Mutations in filamin 1 prevent migration of cerebral cortical neurons in human periventricular heterotopia. Neuron 21: 1315-1325 (1998).

Gajecka M, Mackay KL, Shaffer LG: Monosomy 1 p36 deletion syndrome. Am J Med Genet C Semin Med Genet 145:346-356 (2007).

-Gawlik-Kuklinska K, Wierzba J, Wozniak A, Iliszko M, Debiec-Rychter M, DubaniewiczWybieralska M, Limon J: Periventricular heterotopia in a boy with interstitial deletion of chromosome 4p. Eur J Med Genet 51:165171 (2008).

-Grosso S, Fichera M, Galesi O, Luciano D, Pucci $\mathrm{L}$, et al: Bilateral periventricular nodular heterotopia and lissencephaly in an infant with unbalanced $\mathrm{t}(12 ; 17)(\mathrm{q} 24.31 ; \mathrm{p} 13.3)$ translocation. Dev Med Child Neurol 50:473-476 (2008).

-Jernigan TL, Bellugi U: Anomalous brain morphology on magnetic resonance images in Williams syndrome and Down syndrome. Arch Neurol 47:529-533 (1990).

-Kiehl TR, Chow EW, Mikulis DJ, George SR, Bassett AS: Neuropathologic features in adults with 22q11.2 deletion syndrome. Cereb Cortex 19:153-164 (2008).
Kraynack NC, Hostoffer RW, Robin NH: Agenesis of the corpus callosum associated with DiGeorge-velocardiofacial syndrome: a case report and review of the literature. J Child Neurol 14:754-756 (1999).

- Lachlan KL, Collinson MN, Sandford RO, van Zyl B, Jacobs PA, Thomas NS: Functional disomy resulting from duplications of distal $\mathrm{Xq}$ in four unrelated patients. Hum Genet 115:399-408 (2004).

Leeflang EP, Marsh SE, Parrini E, Moro F, Pilz $D$, et al: Patient with bilateral periventricular nodular heterotopia and polymicrogyria with apparently balanced reciprocal translocation $\mathrm{t}(1 ; 6)(\mathrm{p} 12 ; \mathrm{p} 12.2)$ that interrupts the mannosidase alpha, class $1 \mathrm{~A}$, and glutathione S-transferase A2 genes. J Med Genet 40: e128 (2003).

Livak KJ, Schmittgen TD: Analysis of relative gene expression data using real-time quantitative PCR and the 2(-Delta Delta C(T)) Method. Methods 25:402-408 (2001).

- Marshall CR, Young EJ, Pani AM, Freckmann ML, Lacassie Y, et al: Infantile spasms is associated with deletion of the MAGI2 gene on chromosome 7q11.23-q21.11. Am J Hum Genet 83:106-111 (2008).

Mercuri E, Atkinson J, Braddick O, Rutherford MA, Cowan FM, et al: Chiari I malformation in asymptomatic young children with Williams syndrome: clinical and MRI study. Eur J Paediatr Neurol 1:177-181 (1997).

Moro F, Pisano T, Bernardina BD, Polli R, Murgia $\mathrm{A}$, et al: Periventricular heterotopia in fragile X syndrome. Neurology 67:713-715 (2006).

-Nannya Y, Sanada M, Nakazaki K, Hosoya N, Wang L, et al: A robust algorithm for copy number detection using high-density oligonucleotide single nucleotide polymorphism genotyping arrays. Cancer Res 65:6071-6079 (2005).

-Neal J, Apse K, Sahin M, Walsh CA, Sheen VL: Deletion of chromosome 1p36 is associated with periventricular nodular heterotopia. Am J Med Genet A 140:1692-1695 (2006).

Ozawa H, Osawa M, Nagai T, Sakura N: Steroid sulfatase deficiency with bilateral periventricular nodular heterotopia. Pediatr Neurol 34:239-241 (2006).

Parrini E, Ramazzotti A, Dobyns WB, Mei D, Moro F, et al: Periventricular heterotopia: phenotypic heterogeneity and correlation with Filamin A mutations. Brain 129:18921906 (2006).
Robin NH, Taylor CJ, McDonald-McGinn DM, Zackai EH, Bingham P, et al: Polymicrogyria and deletion 22q11.2 syndrome: window to the etiology of a common cortical malformation. Am J Med Genet A 140:2416-2425 (2006).

Ruggieri M, Spalice A, Polizzi A, Roggini M, Iannetti P: Bilateral periventricular nodular heterotopia with amniotic band syndrome. Pediatr Neurol 36:407-410 (2007).

-Saito S, Kawamura R, Kosho T, Shimizu T, Aoyama K, et al: Bilateral perisylvian polymicrogyria, periventricular nodular heterotopia, and left ventricular noncompaction in a girl with 10.5-11.1 Mb terminal deletion of 1p36. Am J Med Genet A 146A:2891-2897 (2008).

- Sheen VL, Dixon PH, Fox JW, Hong SE, Kinton $\mathrm{L}$, et al: Mutations in the X-linked filamin 1 gene cause periventricular nodular heterotopia in males as well as in females. Hum Mol Genet 10:1775-1783 (2001).

-Sheen VL, Wheless JW, Bodell A, Braverman E, Cotter PD, et al: Periventricular heterotopia associated with chromosome $5 \mathrm{p}$ anomalies. Neurology 60:1033-1036 (2003).

-Sheen VL, Ganesh VS, Topcu M, Sebire G, Bodell A, et al: Mutations in ARFGEF2 implicate vesicle trafficking in neural progenitor proliferation and migration in the human cerebral cortex. Nat Genet 36:69-76 (2004).

-Sheen VL, Jansen A, Chen MH, Parrini E, Morgan T, et al: Filamin A mutations cause periventricular heterotopia with Ehlers-Danlos syndrome. Neurology 64:254-262 (2005).

- Spinosa MJ, Liberalesso PB, Vieira SC, Lohr A Jr: De Morsier syndrome associated with periventricular nodular heterotopia: case report. Arq Neuropsiquiatr 65:693-696 (2007).

-Stock AD, Spallone PA, Dennis TR, Netski D, Morris CA, Mervis CB, Hobart HH: Heat shock protein 27 gene: chromosomal and molecular location and relationship to Williams syndrome. Am J Med Genet A 120A:320-325 (2003).

Tsao CY, Wenger GD, Bartholomew DW: Cri du chat syndrome and complex karyotype in a patient with infantile spasms, hypsarrhythmia, nonketotic hyperglycinemia, and heterotopia. Am J Med Genet A 134A:198-201 (2005).

Vissers LE, Veltman JA, van Kessel AG, Brunner HG: Identification of disease genes by whole genome CGH arrays. Hum Mol Genet 14 Spec No. 2:R215-R223 (2005). 